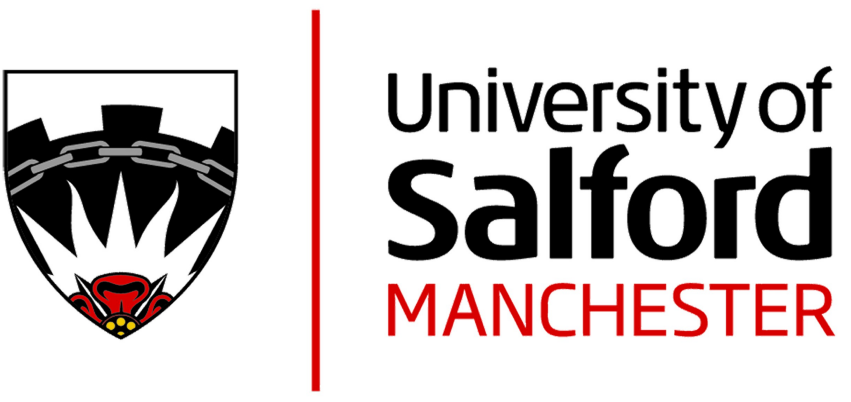

\title{
A literature review on the experience of long-term mental illness
}

Collier, EH and Grant, MJ

http://dx.doi.org/10.1080/01612840.2017.1404169

\begin{tabular}{|l|l|}
\hline Title & A literature review on the experience of long-term mental illness \\
\hline Authors & Collier, EH and Grant, MJ \\
\hline Type & Article \\
\hline URL & This version is available at: http://usir.salford.ac.uk/45232/ \\
\hline Published Date & 2018 \\
\hline
\end{tabular}

USIR is a digital collection of the research output of the University of Salford. Where copyright permits, full text material held in the repository is made freely available online and can be read, downloaded and copied for non-commercial private study or research purposes. Please check the manuscript for any further copyright restrictions.

For more information, including our policy and submission procedure, please contact the Repository Team at: $\underline{\text { usir@ } @ \text { salford.ac.uk. }}$ 


\title{
A literature review on the experience of long-term mental illness
}

\begin{abstract}
Purpose To illuminate long-term experiences of mental illness from both research and autobiographical accounts. Design A literature review of English-language papers, 19502014, relating to the experience of long-term mental illness indexed in Ageinfo, AMED, ASSIA, British Nursing Index (BNI), CINAHL, MEDLINE, Psychextra and PsychInfo. Findings Twenty-five research papers and nine autobiographic accounts met the review criteria. Thematic analysis revealed nine themes: fear, explanation seeking, stigma, disability, coping strategies, control, support, change and learning, and life history. Specific gaps of note relate to age differences, acknowledgement of longevity of mental illnesses, and different cultural perspectives. Research Implications There is an absence of longitudinal studies focused on experiences of long-term mental illness. The considerable length-of-time implicated in the experiences suggests that more individual life experience rather than illness focused studies are needed, enabling a holistic understanding. This includes studies from cultures other than the western world. Greater transparency is needed in justifying age inclusions or passive exclusion of older peoples' perspectives. Practical Implications Knowledge of long-term mental illness experiences is of great importance to mental health practitioners. Evidence-based services cannot be provided if we do not have an holistic understanding of long-term mental illness. Social Implications This review questions our ability to provide effective support for those experiencing long-term mental illness, in particular older people and different cultural perspectives. Originality/Value There appear to be no literature reviews that focus on the individual experience of long-term mental illness. It highlights the surprisingly small number of research studies available to inform mental health practitioners.
\end{abstract}

The prevalence of mental illness worldwide is thought to be around $25 \%$ in both developed and undeveloped countries (World Health Organisation, (WHO) 2013). The term mental illness is used throughout this paper to refer to the medical construct of mental distress as defined by diagnostic manuals traditionally used in research. However, mental illness has also been conceptualised as a disability (Sayce, 2000; Sayce \& Boardman, 2008) because of its long-term effects. High proportions of people with long-term mental illness are seen in community settings and have been described as a neglected majority living without effective support (Sainsbury Centre for Mental Health, 2005; The Schizophrenia 
Commission, 2012). To provide effective support we need first to listen to and understand what is being experienced (Jensen \& Wadkins 2007). Service users value therapeutic relationships with nurses but call for more evidence on the human experience of mental illness (DH 2006; Butterworth \& Shaw, 2017). Although during the last decade recovery rather than 'illness' tends to be the focus of much mental health discourse and policy in western cultures, this does not necessarily represent a worldwide context. We therefore focus on mental illness experience in this paper, which is perhaps more universally understood. This literature review (Grant \& Booth, 2009) therefore aims to determine what the academic literature can tell us about the experience of long-term mental illness.

\section{Search Strategy}

Comprehensive literature searches were conducted in 2010, updated in April 2014, using subject headings and keywords related to 'experience' (Experience, Perspective, Subjective), 'mental illness' (subject heading: mental disorders), and 'long-term' (life course, lifespan, longitudinal) in the bibliographic databases Ageinfo, AMED, ASSIA, British Nursing Index (BNI), CINAHL, MEDLINE, Psychextra and PsychInfo .

\section{Inclusion Criteria}

Research studies focused on long-term mental illness in adults (18 years and over), published in English, 19502014. Autobiographical accounts were also included as they provide storied knowing that add to the depth of knowledge provided by 'distanced' researchers (Smith, 1999).

\section{Exclusion Criteria}

Papers were excluded that focused on generalised quality of life and experience of-hospital/treatment or were concerned solely with adolescent, work-force or post-partum experiences of mental illness. Those whose primary focus was the experience of recovery (rather than the experience of mental illness) were also excluded due to the semantic problems with the concept of recovery and the different meanings debated (Collier, 2010).

\section{Reviewed Papers}


The search found 7765 papers. A review of all the titles and abstracts against the inclusion/exclusion criterion resulted in the identification of 20 relevant papers. A further 14 papers were located via citation tracking, resulting in a total of 34 papers subjected to full review.

\section{Findings}

Thirty-four papers were identified as meeting the review inclusion criteria: 9-autobiographical accounts and 25 research papers. The research papers were published between 1994 and 2014; the majority of which (20) were post 2000. The papers represented the US (7 research, 7 autobiographical), UK (4 research, 1 autobiographical), Australia (1 research, 1 autobiographical), New Zealand (1 research), Thailand (1 research), Taiwan (1 research), Canada (2 research) and Sweden (8). Between four and sixty people participated in all, except one of the studies, which surveyed 166 people (Ritsher et al., 1997).

A thematic analysis of the papers was carried out with reference to Braun \& Clarke (2006). Initial coding of the recurring themes in the findings of each paper were first listed, then compared across papers. The common shared themes across papers are shown in table 1. 
Table 1. Thematic Analysis of Papers

\begin{tabular}{|c|c|c|}
\hline Initial coding across individual papers & Coding & Overarching Them \\
\hline failure, being ill, fearful, lose children, gaining weight & Fear & Fear \\
\hline negative stereotypes, being judged, discrimination, shame & Stigma & Stigma \\
\hline silence, hidden truth & Privacy & Stigma \\
\hline history of abuse, young adulthood & Early life & Life history \\
\hline abnormality, less bizarre & normality & Stigma \\
\hline stress, exhaustion & impairment & Disability \\
\hline $\begin{array}{l}\text { future, dwindling aspirations, imagine a future, one day at a ti } \\
\text { goals, aspirations, standing still }\end{array}$ & Coping & Coping strategies \\
\hline $\begin{array}{l}\text { (isolation, empty and lost, lack of care, rejection, restrictions, } \\
\text { survive, pride, grief, failed jobs, mistrust }\end{array}$ & Loneliness & Disability \\
\hline abuse, painful memories, catastrophe & Trauma & Life history \\
\hline $\begin{array}{l}\text { obtain diagnosis, accept reject diagnosis, disagreement with d } \\
\text { of life, no language to explain, arbitrary sanity measure }\end{array}$ & explanation & Explanation seeking \\
\hline control, restrictions (see loneliness) make lists, plan time, org & structure & Control \\
\hline powerless, resigned lack confidence, no voice & Power & Control \\
\hline $\mathrm{t}$ animals, medication and treatment, lack of support, , family, & Support & Support \\
\hline suicide, distress, angry sad, change (come to terms) & Change & Change and learning \\
\hline (accomplishment achievement work, older and wise therapy $\mathrm{h}$ & Learning & Change and learning \\
\hline Initiative, determination, social disadvantage, pessimism, tria & Control & Control \\
\hline
\end{tabular}




\section{Methodological Issues}

The different methods used in the research studies can be seen in Table 2 .

Table 2. Methodology of Research Studies

\begin{tabular}{|l|l|l|l|l|}
\hline Ethnography & Grounded theory & Phenomenology Qualitative resea & Other \\
\hline Erdner et al 2002 & Karp 1994 & Hedelin \& Strandmark 20 & Tryssenaar al & Chafetz 1996 \\
\hline Erdner et al 2005 & Lewis 1995 & Hedelin \& Jons & Roe et al 2004 & Chernomas \\
\hline Erdner et al 2009 & Repper \& Perkins 1 & Nyström et al 2002 & Wang 2011 & Ritsher et al 1997 \\
\hline & & McCann \& Clarke 2004 & & Thompson et al \\
\hline & & Broussard 2005 & & \\
\hline & & Nehls \& Sallmann 2005 & & \\
\hline & & Stigsdotter Nyström \& Ny & & \\
\hline & & Allan \& Dixon 2009 & & \\
\hline & & Sanseeha et al 2009 & & \\
\hline
\end{tabular}

Seven studies required long-term duration of mental illness as an inclusion criterion-(Chafetz, 1996; Erdner et al., 2002; Tryssenaar et al., 2003; Erdner et al., 2005; Thompson et al., 2008; Erdner et al., 2009; McKay, 2010), but only three provided definitions. These are: in treatment for more than two years (Thompson et al., 2008), illness for more than five years (Erdner et al., 2009), and illness for a minimum of 15 years (Tryssenaar et al., 2003). However, studies using the terms 'severe' or 'serious', (but not defining long-term as an inclusion), report significantly longer durations: longterm contact with mental health services for more than ten years (Repper et al., 1998), more than 30 years (Chernomas $e t$ al., 2000), 10-22 years (Erdner et al., 2002), 15-40 years (Nyström et al., 2002), 1-10 years

(Sanseeha et al., 2009), 50 years (McKay, 2010), 1-32 years (mean of 8.8) (Lester \& Tritter, 2005) and 1-23 years (Broussard, 2005).

The age range of participants was 19-92. Table 3 summarises the age inclusions and characteristics of the research studies. 
Table 3. Age Inclusions and Subsequent Age Characteristics of Research Study Participants

\begin{tabular}{|c|c|c|}
\hline Author & Age inclusion crit & Age characteristics pf \\
\hline McCann \& Clarke, 2004 & 'young adults' & Not given \\
\hline Roe et al., 2004 & $18-55$ & $20-39$ \\
\hline Erdner et al., 2009 & $26-65$ & Not given \\
\hline Erdner et al., 2002 & $30-63$ & Not given \\
\hline Chafetz, 1996 ; Broussard, 2005 ; Thompson et al, & Over 18 & Up to 57 \\
\hline Tryssenaar et al., 2003 & Over 35 & $37-64$ \\
\hline Allan \& Dixon 2009 & Over 65 & $69-82$ \\
\hline Martinsson et al 2012 & Over 70 & $71-75$ \\
\hline Lester \& Tritter, 2005 & None & 19-61 (mean 38) \\
\hline Nehls \& Sallmann, 2005 & None & $19-65$ \\
\hline Stigsdotter-Nyström \& Nyström 2007 & None & $19-67$ \\
\hline Karp, 1994 & None & $20 \mathrm{~s}-50 \mathrm{~s}$ \\
\hline Lewis, 1995 & None & $20-70$ \\
\hline Erdner et al., 2005 & None & $21-57$ \\
\hline Chernomas et al, 2000 & None & 21 -over 60 \\
\hline Repper et al., 1998 & None & $25-65$ \\
\hline Wang, 2011 & None & $26-57$ \\
\hline Ritsher et al., 1997 & None & $29-52$ \\
\hline Nyström et al., 2002 & None & $38-55$ \\
\hline McKay 2010 & None & $42-74$ \\
\hline Hedelin \& Jonsson, 2003 & None & $71-92 *$ \\
\hline Hedelin \& Strandmark, 2001 & None & $75-92 *$ \\
\hline Total ranges & 18 to 'over $70^{\prime}$ & 19-92 \\
\hline
\end{tabular}

*Same data set accessed for 2 papers 


\section{Emergent Themes}

Nine themes relating to the experience of living with long-term mental illness were identified from the thematic analysis. They were: fear, explanation seeking, stigma, disability, coping strategies, control, support, change and learning, and life history.

Fear.

For some fear was a motivator to stay well and out of hospital (Chafetz, 1996). For others, a fear of stress acted as a barrier for seeking work (Chernomas et al., 2000) but most commonly there was a fear of illness:

"It feels frightening not knowing what to do or how to live not to become ill again”. Stigdottir-Nyström \& Nyström (2007) $p 682$

Also, Repper et al., (1998) report:

"I started hallucinating and I worried about it, and then I stripped off in my neighbour's house, I don't know what made me do it, but I thought my husband was trapped in a black bag. I saw it in my hallucinations, it frightened me to death, I didn't know what was going off (W11)." p510

Fear of revisiting distressing experience was also reflected in this theme (McGrath, 1984; Champ, 1998; McCann \& Clarke, 2004; Hutchinson, 2004; Lester \& Tritter, 2005) as was living fearfully in a restricted world (Nehls \& Sallmann, 2005; Stigsdotter-Nyström \& Nyström, 2007; Allan \& Dixon, 2009) and this was exacerbated by abuse experiences (Thompson et al., 2008) and fear of losing children (Walker, 1999).

The perspective of loss featured in relation to loneliness of rejection resulting from stigmatizing public perception and discriminatory judgments (Chernomas et al., 2000; McCann \& Clarke, 2004; Broussard, 2005; Wang 2011; 
Martinsson et al., 2012) and alienation (Hedelin \& Strandmark, 2001; Tryssenaar et al., 2003). Chernomas et al (2000) reports that fear was:

"pervasive in this group so women, no matter what their age, [had] an overwhelming sense of loneliness and isolation." p519

Depression is associated with emptiness and lost feeling (Karp, 1994) and also a lack of love and care in early life (Nyström et al., 2002), but these experiences were not understood by others (McKay, 2010). In addition, wasted years lead to feelings of grief (Hensley, 2002).

\section{Explanation Seeking.}

The development of personal philosophies and explanatory frameworks is evident (Karp, 1994; Lewis, 1995; Chafetz, 1996; Ritsher et al., 1997; Chernomas et al., 2000), though participants couldn't find the language to adequately explain their experiences (Karp, 1994; McKay, 2010).

Explanation seeking includes personal responsibility where looking internally to oneself for explanation is found (McGrath, 1984; Lewis, 1995; Hedelin \& Strandmark, 2001). However, Repper et al. (1998) found that younger people are more likely to look for external explanations though this is not a consistent finding as women (between 21 and 'over 60’) (Chernomas et al., 2000):

'...vacillated between knowing that they were not responsible for the onset of their illness and feeling somehow that they somehow must be responsible'. p1519

Leete (1989) realised only after twenty years that she would survive schizophrenia which was achieved by developing coping mechanisms and taking responsibility for her life. This is in contrast to two recent studies from Thailand and Taiwan that reflect societies based on 'familism' rather than 'individualism' (Sanseeha et al., 2009; Wang, 
2011). Explanation seeking in this context appears to incorporate the concept of Karma within a Buddhist tradition, where illness is punishment for bad deeds in a past life, or 'folk beliefs' which help understand causes. Sanseeha et al. (2009) reports:

"...the participants considered that if black magic was applied to someone then that persons psychological or mental behaviours including emotions would deviate from normality."p308

Searching for an explanation through diagnosis was actively sought and reported by some as bringing relief (Erdner et al., 2005) though Champ (1998) rejected diagnosis of mental illness as cultural conditioning. Hutchinson (2004) interpreted his mental illness as physical illness requiring medication, thus enabling him to distance himself from the stigma associated with mental illness, as was also shown in a Thai context (Sanseeha et al., 2009). However, biological perspectives are not the most common with Ritsher et al. (1997) finding that:

"only about one third of the respondents attributed their problems to chemical imbalance". p1296

There appears to be a complex personal logic relevant to each person's life context that encompasses a variety of concepts relating to different beliefs.

\section{Stigma.}

Stigma is a key theme in Chernomas et al. (2000) and also Wang (2011) which includes shame and is also reflected within the theme of fear (Lundin, 1998; Sanseeha et al., 
2009; Wang, 2011). Societal views were internalised which resulted in self-stigma (Allan \& Dixon, 2009), and as Lundin (1998) indicated:

‘...being mentally ill was out of the question. It could not possibly happen to me.

The stigma of that was unbearable’. p225

The effect of mental illness impeded involvement in social life (Hedelin \& Standmark, 2001; Tryssenaar et al., 2003; Hutchinson, 2004) which resulted in efforts to pass as normal or less bizarre (Leete, 1989; Karp, 1994; Chafetz, 1996; Repper et al., 1998; Walker, 1999; Tryssenaar et al., 2003; Lester \& Tritter, 2005; Broussard, 2005). This also has a relationship with privacy, making distinctions between private and public selves and not sharing experiences because of expectations of how others might react, including close family (Karp, 1994; Lundin, 1998; Chernomas et al., 2000; Hedelin \& Strandmark, 2001;

Broussard, 2005). Stigma imposed by others reinforced feelings of fear and failure (Champ, 1998; Chernomas et al., 2000; Sanseeha et al., 2009; Martinsson et al 2012):

“...they felt judged as inferior and felt that they did not belong no matter where they went”. Chernomas et al. (2000) p1518

This was a particular problem for one participant in Wang (2011) study who carried the feeling of shame from ten years previously when taken out in public '... because of the collective label (the psychiatric hospital's name) on the uniform she wore, she was humiliated as a member of the stigmatized group' p429.

Feelings of failure lead to severely disrupted patterns of occupation (Sanseeha et al., 2009; McKay, 2010). However workforce engagement remained important as a positive goal as working was a 'normal' activity that made life easier by being accepted as part of a community (Leete, 1989; McKay, 2010). McKay (2010) suggests a victim role was reinforced by challenging attitudes from others which was in contrast to their perception of the participants as experts in their own lives. 


\section{Disability.}

Disability affected all aspects of life in relation to both individual impairment due to experiences, and social disadvantage due to outside influences (Leete, 1989; Champ, 1998; Erdner et al., 2002; Tryssenaar et al., 2003; Nehls \& Sallman, 2005; Lester \& Tritter, 2005; Erdner et al., 2005).

Individuals reported invalidated opinions, not being believed or taken seriously and without a voice (McGrath, 1984; Leete, 1989; Chernomas et al., 2000; Sholtis, 2002; Tryssenaar et al., 2003; Lester \& Tritter, 2005; Wang, 2011) when what they needed was to have their stories heard (Tryssenaar et al., 2003; Nehls \& Sallman, 2005). Feelings of pressure from authoritative professionals was included in this (McGrath, 1984; Tryssenaar et al., 2003) which is illustrated by one participant's conversation with a psychiatrist:

“...so he said 'well I'll make a deal with you...you agree to a series of shock treatments and if they don't work then I'll think about hypnosis'... I said 'well I'll make a deal with you ... you agree to hypnosis, if that doesn't work, I'll think about shock treatments...he said' I'm the doctor'...I said 'I know, and I'm the patient." Tryssenaar et al. (2003) p26

Lower function and increased disability scores was found in one paper when more care was available (Chafetz, 1996). It is possible that care was sought by the participants in this study because they were struggling with independence, or alternatively the results could be explained by the deskilling process of institutionalisation. Nevertheless Chafetz (1996) concludes that illness management is influenced by individual learning and choice making. Others have found that limitations in functioning are adapted to (Thompson et al., 2008), and people can respond to the restrictions that symptoms impose (Erdner et al., 2002).

Champ (1998) states that: 
"having a disability has changed the way I view myself as a worker in society and redefined the role and value I attributed to work in my life". p56

\section{Coping Strategies.}

$30 \%$ people in the Ritsher et al. (1997) survey indicated that severe mental illness had significantly shaped them but illness occupied the mind frequently in only 28 of the 166

(17\%); their preoccupations were usual life activities and pleasures rather than mental illness. Evidence of personal coping strategies (McKay, 2010) (particularly notable within the autobiographical accounts) illustrate different complex self-care strategies for control and organisation such as testing out expectations, exercise, accepting voices but not being impressed by them, work and setting goals, engaging in education and telling their stories

(Leete, 1989; Hensley, 2002; Walen, 2002; Sholtis, 2002; Roe et al., 2004; Hutchinson,

2004).

Identity and self-image is challenged when adapting to experiences of illness

(McGrath, 1984; Karp, 1994; Chernomas et al., 2000; Erdner et al., 2005; Lester \& Tritter, 2005). For some pride was reclaimed in survival (Leete, 1989; Champ, 1998), though over time this resulted in emotional exhaustion as Sholtis (2002) says:

'You have to go forward or else, well, it would be hard to live your life on a board only about 10 inches wide. So you learn to swim, and that is how it is with mental illness, you just do it. It's exhausting but you do it. 'p289

\section{Control.}

Coping strategies implicates individual attempts to achieve control over one's life. Taking control within care settings is also illustrated though this is difficult as Martinsson et al (2012) report:

'One was at mercy of others; powerlessly watching while others controlled one's life.'

(p4) 
Wang 2011 report one attempt to overcome powerlessness in relation to pressure to-conform to a patient role as '...very unusual and exceptional' (p426).

Determination and desire to win is required for recovery (Chernomas et al., 2000; Roe et al., 2004; Hutchinson, 2004) and creating an environment of structure and routine can create a sense of control (Leete, 1989; Erdner et al., 2002; Hensley, 2002; Tryssenaar et al., 2003; Roe et al., 2004). In Sanseeha et al. (2009), it is noted that one participant had a: “...realisation that they had to try to manage the illness by adjusting their self-care activities and social behaviours, encouraging themselves, seeking mental refuge and following dharma or Buddhist morality to reduce the disorders negative impact on their life."

Sanseeha et al. (2009) p309

In three studies the feelings of self-loathing, detestation, vulnerability and lack of confidence (Stigsdotter-Nyström \& Nyström, 2007; Allan \& Dixon, 2009; Wang, 2011) serve to control participants' lives. Living behind an 'invisible screen of glass' and wanting to die (Stigsdotter-Nyström \& Nyström, 2007) imply control by one’s own feelings though typically decisions were made without their involvement:

“...conversations among caregivers and family members are generally held without regarding the will, interest or ambitions of oneself." Martinsson et al.

(2012) p5

Setting goals for self-improvement provides motivation for getting up each day and something to look forward to (Leete, 1989). Similarly, despite periods of sickness goals and aspirations can be achieved (McKay, 2010). 


\section{Support.}

Personal relationships with family, friends, professionals or animals are implicated in this theme (Ritsher et al., 1997). However, these could be both constructive and destructive (McKay, 2010) and implicated in the violation of mental health, as Erdner et al. (2009) indicates:

“...the participants lives could have been different if there had been more harmony, especially between their parents when they were children." p57

Martinsson et al. (2012) notes that asking for help moves one towards seeking respect, McKay (2010) finding that support was mainly achieved through a self-created network of people in similar circumstances who remained ignorant of any professional support services or aware of the limitations of these where available.

Joy and meaning in life was found through relationships with animals, particularly as they didn't make demands (Walen, 2002; Erdner et al., 2009), as Walen (2002) says:

“...I stare into the eyes of one of those puppies. They are the only source of gladness right now." $p 421$

However, despite the positive benefits to be accrued from relationships, StigsdotterNyström \& Nyström (2007) note that:

“long-term illness makes it difficult to maintain relationships which leads to a feeling of meaningless in life." p683

Loneliness and isolation from hospitalisation, avoidance, difficulty and/or loss of relationships due to illness can be problematic (Chernomas et al., 2000; Nyström et al., 2002; Erdner et al., 2002; Hedelin \& Jonsson, 2003; McCann \& Clarke, 2004; Erdner et al., 2005; Thompson et al., 2008; Erdner et al., 2009). Isolation and loneliness also reflects an inability to establish friendships and dissatisfaction with interpersonal relationships when wanting to appear normal 
(Erdner et al., 2002; Broussard, 2005; Stigsdotter-Nyström \& Nyström, 2007; Allan \& Dixon 2009). Allan \& Dixon 2009 note:

"They withdraw from other people, which resulted in them feeling alone and isolated." 868

\section{Change and Learning.}

There is contrasting evidence in relation to change and learning: on the one hand, the inability to look forward, reduced aspirations and pessimism but also the ability to anticipate the future and to learn (Repper et al., 1998; Hedelin \& Strandmark, 2001; Tryssenaar et al., 2003; Erdner et al., 2005; Thompson et al., 2008). However, the positive aspects seem to have greater prevalence with evidence of a developing ability to cope with symptoms, determination, individual learning, management of illness, and hopes for the future also demonstrated (Chafetz, 1996; Ritsher et al., 1997; Tryssenaar et al., 2003; Roe et al., 2004; Wang 2011). Tryssenaar et al. (2003) indicates both an increasing hopelessness with ageing and improved coping as people age and learn through practice. Similarly, Chafetz (1996) notes that as people get older they were found to improve over time.

The female participants in the McKay (2010) study felt happier after surviving adverse circumstances for a long time, which was in contrast to their expectations, and they became experts in their own lives. The autobiographical accounts show this in particular, where the authors are quite positive and demonstrate learning about what works, that is: using medication and behaviours to manage situations, skills and improving self, how to manage thoughts, learning from feedback, learning to concentrate, to be careful and be persistent (McGrath, 1984; Leete, 1989; Lundin, 1998; Champ, 1998; Walen, 2002; Hensley, 2002;

Sholtis, 2002; Hutchinson, 2004). Champ (1998) states that:

"I have learned over the years that it is only by owning and embracing the strange world within from which schizophrenia arises that I have any chance of controlling its manifestations or preventing it from overwhelming me. ”p55 
Although experience is lengthy and can be a fearful journey (McGrath, 1984), the evidence shows a process of learning, whether changing personal attitudes and responses to experiences (Leete, 1989; Champ, 1998), embracing a strange world (Champ, 1998), going easy on and accepting oneself (Hensley, 2002), or going through the trial and error of treatments (Leete, 1989; Hutchinson, 2004).

\section{Life History.}

Thirteen research papers demonstrated reference back to childhood, adolescence or early adulthood and found significant experiences of abuse or trauma (Karp, 1994; Chafetz,

1996; Ritsher et al., 1997; Repper et al., 1998; Chernomas et al., 2000; Hedelin \& Strandmark, 2001; Nyström et al., 2002; Tryssenaar et al., 2003; Hedelin \& Jonsson, 2003; Nehls \& Sallmann, 2005; Thompson et al., 2008; Erdner et al., 2009; McKay 2010) This theme is also reflected in personal accounts (Champ, 1998; Walker, 1999; Hensley, 2002;

Walen, 2002). One participant in Nehls \& Sallmann (2005);

“...saw little hope of breaking out of a vicious cycle of multiple traumas. Her early memories shaped her view of the past the present and the future."p370 Similarly, no starting point could be identified in the experience of depression (Karp, 1994). The impact of hospitalisation and lasting and disabling effects of treatment had a traumatic effect (Champ, 1998; Nehls \& Sallmann, 2005; McKay, 2010). Experiences and events from the past were relived in the present for both older people (Hedelin \& Strandmark,

2001; Hedelin \& Jonsson, 2003) and young people (McCann \& Clarke, 2004). Erdner et al.

(2009) found:

“...the participants were attempting to become reconciled with their early life experiences and find meaning in their present lives. " p57 


\section{Discussion}

This review set out to uncover the experiences of MI through the life course and the "listened to" and "heard" human experience of long term MI. The earliest paper identified for this review was published in 1994. Studies published before this related to aetiology and medical constructs (Karp, 1994; Lewis, 1995). The subsequent emergence of reports focused on subjective experience may reflect changing international policy whereby the role of the service user is redefined and the voice of personal experience sought out. Our thematic analysis revealed nine themes: fear, explanation seeking, stigma, disability, coping, control, support, change and development and life history. The anomaly between the relatively short definitions of long-term in contrast to durations of MIH described in the findings is reinforced by the recent conceptualisation of severe and persistent MIH as a minimum of one year (Manderscheid et al., 2010). Seeking to quantify long-term MI risks overlooking the implications for those whose experience is the whole of their [adult] life (Collier, 2012); this review evidencing long-term experiences in excess of 30 and up to 50 years (Chernomas et al., 2000; Erdner et al., 2002; Nystrom et al., 2002; McKay, 2010). However, most (21 papers) of the located research focuses on the age range 18-64. Brown \& Harris raised concerns in 1978 that the predominant concern of studies of 'chronic illness' was the middle years of life with a recommendation to look to wider aspects of the lifecourse, but this doesn't appear to have been achieved in relation to the academic literature on the long term experience of mental illness. This is important as recent policy has advocated a shift to life course approaches to health (WHO, 2000; DH, 2011), but there is clearly limited research to inform our understanding of the experience of long term mental illness. Most of the evidence is gathered at single points in time, limiting what it can tell us about to the temporal nature of the individual life course. Life course theory focuses on experientially different individual life trajectory's that occur within continually changing social systems over time (Shanahan \& Macmillan, 2008; Elder \& Giele, 2009), which the life history theme alludes to. In the absence of qualitative longitudinal studies, a life context approach may be a useful alternative in making sense of long term mental illness, where the unifying framework of a person's life helps synthesise several complex theoretical positions into a single entity (Davidson \& Strauss, 1995). Such an approach has shown that older people with long term mental illness can be better and worse at the same time (Collier, 2012), a concept which might account for the contradictory evidence in the change and learning theme. Nevertheless, the change and learning theme suggests that the subtle influences and change in relation to mental health happen over extended periods of time. It might follow therefore that 
older people would be able to tell us the most, yet they are the least represented as has been observed elsewhere (Sainsbury Centre for Mental Health, 2005; McKay, 2010; Collier \& Edwards, 2013).

Those papers that do not actively exclude older people frequently do not have anyone over 65 participating possibly as a consequence of locating recruitment predominantly within age defined mental health services. This leads to a passive exclusion of older people from research studies located in 'working age' services. This has to change if we are to understand the experience of long term mental illness through the lifecourse more fully and provide effective care particularly for older people. During the next 35 years the proportion of the world's older adults is estimated to rise to $22 \%$ (doubled from 11\% in 2000) to approximately 2 billion people over the age of 60 (WHO 2013). Mental or neurological disorder is experienced by over $20 \%$ of those over the age of 60 and account for around $6.6 \%$ of all disability among the over 60s (WHO, 2013). However many of these people will have experienced mental illness from younger adult hood as evidenced in this review but their needs are still not well recognised or addressed in policy (Wrigley et al, 2006; Clifton et al. 2013).

The contradictions evidenced in the theme of change and learning shows that the experience is not straightforward. It suggests that both positive and negative processes are occurring at the same time, with the language available to articulate these experiences limited. While some people are limited by processes of self-stigma and fear, others address powerlessness though goal setting. This occurs within varied sense making frameworks revealed within the explanation seeking theme of this review and supported in the life history theme where starting points for mental ill health were ambiguous.

The themes of coping strategies and support demonstrate a real strength and resilience of the individuals represented in the studies found and indicate the adaptations people make over time; the personal responsibility taken and the efforts made towards selfimprovement and self-help. These characteristics provide support for recovery focused mental health policies popular worldwide, but which are perhaps less developed in parts of the world other than westernised countries (Nxumalo-Ngubane, 2016). That many feel they do not have a voice (Sayce, 2000) is evident in the disability theme and by the virtual absence in the reviewed papers of those from non-western cultures. The review findings 
strongly reflect western perspectives with only two recent additions to the literature representing an Asian perspective (Sanseeha et al., 2009, Wang, 2011).

Themes of explanation seeking, stigma, control and change and learning are shared with the western literature and there is a seemingly universal effort to find much more idiosyncratic narrative of mental illness, in contrast to the traditional medical model. Power and powerlessness in particular is apparent and Wang's (2011) research challenges the considerable international influence and power of the medical model of mental illness and its imposition on Asian cultures.

The Asian papers although similar in the broad themes offer details that counter western narratives; a key difference is reference to cultures based on familism. Familism may help understand differences in cultures that value individualism, however, given that the theme of support highlights how relationships can violate mental health, understanding the relational context of personal experiences of mental illness clearly needs further exploration across cultures.

\section{Conclusion}

Despite historical calls for consideration of the wider aspects of the lifecourse in chronic illness, the evidence in this review would suggest that in long-term mental illness this has not to any great extent, been achieved. This review evidences the personal experience of long-term mental illness and highlights that most research is westernised, and focused on adults aged 18-64. It advocates a shift in focus from illness per se to the individual in particular, employing

longitudinal or lifecourse perspectives to provide us with a more comprehensive understanding of relevant issues of living with mental illness into later life, an issue which warrants closer scrutiny within a globally ageing population context.

\section{References}

Allan, J. and Dixon, A. (2009), “Older women's experiences of depression: a hermeneutic phenomenological study”, Journal of Psychiatric and Mental Health Nursing, Vol. 16, pp. 865-873.

Braun, V. and Clarke, V. (2006), “Using thematic analysis in psychology”, Qualitative 
Research in Psychology, Vol. 3, pp. 77-101.

British psychological society (2000) Recent advanced in understanding mental illness and psychotic experiences. BPS, Leicester.

http://www.schizophrenia.com/research/Rep03.pdf

Broussard, B. (2005), "Women's experiences of bulimia nervosa", Journal of Advanced Nursing, Vol. 49 No. 1, pp. 43-50.

Brown, G.W. and Harris, T.O. (1978), The Social Origins of Depression, Tavistock Publications Ltd., London.

Butterworth, T., Shaw, T. (2017) Playing our Part. The work of graduate and registered mental health nurses. An independent review by the Foundation of Nursing Studies Foundation of Nursing Studies, London.

Chafetz, L. (1996), “The experience of severe mental illness, a life history approach”, Archives in Psychiatric Nursing, Vol 10 No. 1, pp. 24-31.

Champ, S. (1998), “A most precious thread”, Australian and New Zealand Journal of Mental Health Nursing, Vol. 7 No. 2, pp. 54-59.

Chernomas, W.M., Clarke, D.E. and Chisholm, F.A. (2000), "Perspectives of women living with schizophrenia", Psychiatric Services, Vol. 51 No. 12, pp. 1517-1721.

Collier E. (2010), “The confusion of recovery: one solution”, International Journal of Mental Health Nursing, Vol. 19, pp. 16-21.

Collier, E. (2012), “A biographical narrative study exploring mental ill health through the lifecourse”, Unpublished PhD Thesis, University of Salford, Salford.

Collier, E. and Edwards, S. (2013), “The abandoned illness: where is the voice of older adults? British Journal of Mental Health Nursing, Vol. 2 No 1, pp. 15.

Clifton, A., Marples, G., Clarke, A. (2013) Ageing with a serious mental illness: a literature and policy review. Mental Health Review Journal 18(2):65-72 
Davidson, L. Strauss, J.S. (1995) Beyond the biopsychosocial model: integrating disorder, health and recovery. Psychiatry 58(1):44-55.

Department of Health (2006) Chief nursing officers review of Mental Health Nursing, DH, London.

Department of Health (2011) No Health without Mental Health. A cross-government mental health outcomes strategy for people of all ages. DH, London

Elder, G.H. and Giele, J.Z. (2009 - eds.) The Craft of Lifecourse Research, The Guildford Press, New York.

Erdner, A., Andersson, L., Magnusson, A. and Lütszén, K. (2009), "Varying views of life among people with long-term mental illness", Journal of Psychiatric and Mental Health Nursing, Vol. 16 No. 1, pp. 54-60.

Erdner, A., Magnusson, A., Nyström, M. and Lütszén, K. (2005), “Social and existential alienation experienced by people with long-term mental illness", Scandinavian Journal of Caring Sciences, Vol. 19 No. 4, 373-380.

Erdner, A., Nyström, M., Severinsson, E. and Lützén, K. (2002), "Psychosocial disadvantages in the lives of persons with long-term mental illness living in a Swedish community", Journal of Psychiatric and Mental Health Nursing, Vol. 9 No. 4, pp. 457-463.

Grant, M.J. and Booth, A. (2009), “A typology of reviews: an analysis of 14 review types and associated methodologies", Health Information and Libraries Journal, Vol. 26, pp. 91-108.

Hedelin, B. and Jonsson, I. (2003), "Mutuality as background music in women's lived experience of mental health and depression”, Journal of Psychiatric and Mental Health Nursing, Vol. 10, No. 3, pp. 317-322.

Hedelin, B. and Strandmark, M. (2001) "The meaning of depression from the life world perspective of elderly women", Issues in Mental Health Nursing, Vol. 22, pp. 401420.

Hensley, K. (2002), "Soul in search of self: the lived experience of serious mental illness”, Psychiatric Rehabilitation Journal, Vol. 25 No. 4, pp. 417-420.

Hutchinson, M. (2004), “Surviving dual diagnosis”, Mental Health Today, Vol. Jul/Aug., pp. 34-35.

Karp, D.A. (1994), “Living with depression: illness and identity turning points”, Qualitative Health Research, Vol. 4 No. 1, pp. 6-30. 
Leete, E. (1989), “How I perceive and manage my illness”, Schizophrenia Bulletin, Vol. 15

No. 2, pp. 197-200.

Lester, H. and Tritter, J.Q. (2005), “'Listen to my madness': understanding the experience of people with serious mental illness", Sociology of Health and Illness, Vol. 27 No. 5, pp. 649-669.

Lewis, S.E. (1995), “A search for meaning: making sense of depression”, Journal of Mental Health, Vol. 4 No. 4, pp. 369-382.

Lundin, R. (1998). "Living with mental illness; a personal experience", Cognitive and Behavioral Practice, Vol. 5 No. 2, 223-230.

Martinsson, G., Fagerberg, I., Lindholm, C. and Wiklund-Gustin, L (2012), "Struggling for existence - life situation experiences of older persons with mental disorders", available at: http://dx.doi.org/10.3402/qhw.v7i0.18422 (accessed 9 September 2014)

McCann, T.V. and Clarke, E. (2004), "Embodiment of severe and enduring mental illness; finding meaning in schizophrenia", Issues in Mental Health Nursing, Vol. 25 No 8, pp. 783-798.

McGrath, M.E. (1984), “First person account: where did I go?”,Schizophrenia Bulletin, Vol. 10 No. 4, 638-640.

McKay, E.A. (2010), “'Rip that book up, I've changed': unveiling the experiences of women living with and surviving enduring mental illness”, British Journal of Occupational Therapy, Vol. 73 No 3, pp. 96-105.

Nehls, N., Sallmann, J. (2005), "Women living with a history of physical and/or sexual abuse substance use and mental health problems", Qualitative Health Research, Vol. 15, pp. 365-381.

Nyström, M., Dahlberg, K. and Segesten, K. (2002), “The enigma of severe mental illness: a Swedish perspective", Issues in Mental Health Nursing, Vol. 23 No. 2, pp. 121-134.

Nxumalo-Ngubane, S. (2016) The Experiences, Perceptions and Meaning of Recovery for Swazi women living with Sifo Sengcondvo 'Schizophrenia' Unpublished PhD thesis. University of Salford.

Repper, J., Perkins, R. and Owens, S. (1998), “'I wanted to be a nurse...but I didn’t get that far’: women with serious ongoing mental health problems speak about their lives", 
Journal of Psychiatric and Mental Health Nursing, Vol. 5 No. 6, pp. 505-513.

Ritsher, J.E.B., Coursey, R.D. and Farrell, E.W. (1997), “A survey on issues in the lives of women with severe mental illness", Hospital and Community Psychiatry, Vol. 48 No. 10, pp. 1273-1282

Roe, D., Chopra, M. and Rudnick, A. (2004), "Persons with psychosis as active agents interacting with their disorder", PsychiatricRehabilitation Journal, Vol. 28 No. 2, pp. 122-128.

Sainsbury Centre for Mental Health. (2005), The Neglected Majority: Developing

Intermediate Mental Health Care in Primary Care, Sainsbury Centre, London.

Sanseeha, L., Chontawan, R., Sethabouppha, H., Disayavanish, C. and Turale, S. (2009),

"Illness perspectives of Thais diagnosed with schizophrenia", Nursing and Health Sciences, Vol. 11, pp. 306-311.

Sayce, L. (2000), "From psychiatric patient to citizen overcoming discrimination and social exclusion", Macmillan, London.

Sayce, L. and Boardman, J. (2008), "Disability rights and mental health in the UK: recent developments in the Disability Discrimination Act", Advances in Psychiatric Treatment, Vol. 14, pp. 265-275.

Sholtis, B. (2002), “Managing a mental illness”, Psychiatric Rehabilitation Skills, Vol. 6 No. 3, pp. 287-295.

Smith, B. (1999), "The abyss: exploring depression through the narrative of the self", Qualitative Inquiry, Vol. 5 No. 2, 264-279.

Stigsdotter-Nyström, M.E.S. and Nyström, M. (2007), "Patients experience of recurrent depression", Issues in Mental Health Nursing, Vol. 28, pp. 673-690.

The Schizophrenia Commission (2012) The Abandoned Illness: A Report From The Schizophrenia Commission, Rethink Mental Illness, London.

Thompson, N.C., Hunter, E.E., Murray, L., Ninci, L., Rolfs, E.M. and Pallikkathayil, L.

(2008), "The experience of living with chronic mental illness: a photo voice study", Perspectives in Psychiatric Care, Vol. 44 No. 1, pp. 14-24.

Tryssenaar, J., Chui, A. and Finch, L. (2003), "Growing older: the lived experience of older persons with serious mental illness", Canadian Journal of Community Mental Health, Vol. 22 No. 1, pp. 21-35.

Walen, S. (2002), “It's a funny thing about suicide; a personal experience”, British Journal of 
Guidance and Counselling, Vol. 30 No. 4, pp. 415-430.

Walker, D. (1999), “Journey through paranoia and beyond a personal account”, Journal of orthomolecular Medicine, Vol. 1 No. 3, pp. 158-168.

Wang, J.Y. (2011), “Service users' personal experience and interpretation of mental illness: oriental narratives", International Journal of Social Psychiatry, Vol. 58 No. 4, pp. 425-432.

World Health Organisation (2000) The implications for training of embracing a lifecourse approach to health. WHO, Geneva.

World Health Organisation (2013), "Mental health and older adults: fact sheet no. 381", available at: http://www.who.int/mediacentre/factsheets/fs381/en/ (accessed 9 ${ }^{\text {th }}$ September 2014.

Wrigley, M., Murphy, B., Farrell, M., Cassidy, B., Ryan, M J. (2006) Older people with enduring or recurrent severe mental illness (graduates). A literature review. Irish

Journal of Psychological Medicine 23(4):151-155 